12,13

\title{
Электронное строение и фазовый состав диэлектрических прослоек В многослойной аморфной наноструктуре $\left[(\mathrm{CoFeB})_{60} \mathrm{C}_{40} / \mathrm{SiO}_{2}\right]_{200}$
}

\author{
(C) Э.П. Домашевская ${ }^{1}$, Н.С. Буйлов ${ }^{1}$, В.А. Терехов $^{1}$, К.А. Барков ${ }^{1}$, В.Г. Ситников ${ }^{2}$ \\ ${ }^{1}$ Воронежский государственный университет, \\ Воронеж, Россия \\ ${ }^{2}$ Воронежский государственный технический университет, \\ Воронеж, Россия \\ E-mail: ft@@phys.vsu.ru
}

(Поступила в Редакцию 23 мая 2016 г.)

Многослойная аморфная наноструктура $\left[(\mathrm{CoFeB})_{60} \mathrm{C}_{40} / \mathrm{SiO}_{2}\right]_{200}$ из чередующихся композитных и диэлектрических слоев была получена ионно-лучевым распылением на вращающуюся ситалловую подложку из двух мишеней, одна из которых представляла собой металлическую пластину сплава $\mathrm{Co}_{40} \mathrm{Fe}_{40} \mathrm{~B}_{20}$ со вставками графита. Диэлектрические прослойки напылялись из пластины кварца $\mathrm{SiO}_{2}$ (вторая мишень). Толщины бислоев многослойной наноструктуры (MHC) $(6 \mathrm{~nm})$, состоящие из металлосодержащих композитных слоев с углеродом $(\mathrm{CoFeB})_{60} \mathrm{C}_{40}$ толщиной около $4 \mathrm{~nm}$ и диэлектрических прослоек оксидов кремния толщиной около $2 \mathrm{~nm}$, определялись методом малоугловой дифракции. Результаты экспериментального послойного исследования без разрушения МНС методом ультрамягкой рентгеновской спектроскопии (УМРЭС) показали существенное отклонение стехиометрического состава диэлектрических прослоек от стехиометрии распыляемого кварца в сторону уменьшения содержания кислорода с образованием субоксида $\mathrm{SiO}_{1,3}$. По результатам моделирования $\mathrm{Si} L_{2,3}$-спектров с помощью эталонных спектров известных фаз содержание субоксидной фазы кремния в аморфных диэлектрических прослойках достигает около половины состава прослойки, вторая половина которого приходится на диоксид $\mathrm{SiO}_{2}$.

„Экранирующее“ действие углерода в металлосодержащих слоях проявляется в отсутствии силицидообразования на интерфейсах исследуемой многослойной структуры и должно способствовать увеличению анизотропии их электромагнитных свойств.

Работа выполнена при поддержке Минобрнауки России в рамках государственного задания ВУЗам в сфере научной деятельности на 2014-2016 годы. Проект № 757 и Задание № 3.1868.2014/K.

DOI: 10.21883/FTT.2017.01.43968.205

\section{1. Введение}

Магнитные свойства гетерофазных систем зависят от многих параметров атомного и электронного строения компонент. К основным относится соотношение объемов ферромагнитной и немагнитной фаз, которое влияет на расстояния между наночастицами металлического сплава и, следовательно, на величину магнитного взаимодействия между магнитными моментами гранул. При большом расстоянии между гранулами эта система имеет неупорядоченное пространственное расположение собственных магнитных моментов, и материал находится в суперпарамагнитном состоянии. С увеличением относительного объема ферромагнитной фазы уменьшаются расстояния, возникает обменное взаимодействие между магнитными моментами атомов различных гранул и возникает корреляция магнитных моментов структуры в целом. Это определяет макроферромагнитную природу гетерогенного объекта. Следующим фактором по масштабу влияния на магнитные свойства гетерогенных систем является гомогенность расположения ферромагнитных гранул в структуре пленки. Способ получения и механизм формирования гетерогенной структуры в процессе синтеза пленки определяет исходную гетероген- ность структуры композиционных пленок в плоскости подложки и перпендикулярно ей.

В числе первых работ, посвященных исследованию электрических и магнитных свойств аморфных гранулированных композитов $(\mathrm{CoFeB})_{x}\left(\mathrm{SiO}_{n}\right)_{l 00-x}$, полученных методом ионно-лучевого распыления составных мишеней, в работах $[1,2]$ было установлено, что при увеличении доли металлической фазы $\mathrm{CoFeB}$ с 30 до 59 ат.\% размеры аморфных гранул изменяются от $2-3$ до 5-7 nm и доминирующим механизмом проводимости в композитах является туннелирование. При комнатной температуре в композитах было обнаружено гигантское магнитосопротивление (ГМС), достигающее $4 \%$ в полях 11 Ое, обусловленное спин-зависимым туннелированием электронов между металлическими гранулами. Проведенные магнитные исследования обнаружили наличие суперпарамагнетизма в аморфных композитах $\left(\mathrm{Co}_{41} \mathrm{Fe}_{39} \mathrm{~B}_{20}\right)_{x}\left(\mathrm{SiO}_{2}\right)_{1-x}$.

Далее в наших работах [3,4] на основе данных рентгеновской спектроскопии эмиссии и поглощения в тех же нанокомпозитах $\left(\mathrm{Co}_{41} \mathrm{Fe}_{39} \mathrm{~B}_{20}\right)_{x}\left(\mathrm{SiO}_{2}\right)_{1-x}$, а также в $\left(\mathrm{Co}_{45} \mathrm{Fe}_{45} \mathrm{Zr}_{10}\right)_{x}\left(\mathrm{SiO}_{2}\right)_{1-x}$, благодаря локальности этих методов, было обнаружено межатомное взаимодействие между атомами металлической и диэлектрической ком- 
понент и предложены топологические и энергетические модели нанокомпозитов.

В этих работах было установлено, что в результате твердофазных взаимодействий на межфазных границах гранул образуются сложные оксиды/наноферриты переходных металлов и силикаты/боросиликаты железа и циркония. При этом часть атомов кремния диэлектрической компоненты $\mathrm{SiO}_{2}$ образует кластеры из атомов элементарного кремния, порождающие локализованные состояния в запрещенной зоне диэлектрической матрицы $\mathrm{SiO}_{2}$, которые в значительной степени обеспечивают прыжковую проводимость нанокомпозита наряду с туннелированием. При этом бор принимает участие в межатомных взаимодействиях металлической и диэлектрической компонент, образуя боросиликаты $d$-металлов $[3,4]$.

Многослойные наноструктуры (МНС) из слоев магнитных переходных металлов, чередующихся с немагнитными прослойками, привлекают не меньшее внимание исследователей вследствие их новых и необычных магнитных свойств [5-16]. В частности, в многослойных структурах ферромагнетиков с прослойками немагнитного материала $(\mathrm{Co} / \mathrm{Si})_{n}$ наблюдались периодические изменения магнитного взаимодействия от ферромагнитного к антиферромагнитному между металлическими слоями при изменении толщины прослойки [5]. Комплексное магнитное поведение таких наноструктур обусловлено несколькими конкурирующими взаимодействиями, в том числе обменными взаимодействиями $d$-электронов переходных металлов магнитных слоев, межатомными взаимодействиями атомов магнитных слоев и немагнитных прослоек, которыми и обусловлена значительная вероятность возникновения нелинейных свойств и эффектов сложной системы. Физические свойства многослойных наносистем с толщинами слоев порядка нескольких нанометров во многом определяются структурой и интерфейсными явлениями между различными фазами. В той же работе [5] было показано, что в формировании магнитных свойств большую роль играют межслойные интерфейсы, в которых имеет место уменьшение эффективного магнитного момента атомов Со, ослабление обменного взаимодействия и дисперсия магнитной анизотропии. Вероятной причиной образования интерфейсов авторы называют межслойное перемешивание, происходящее, по оценкам, на глубину до $15 \AA$, и активное воздействие $\mathrm{Si}$ на электронную структуру Сo.

Еще более критическая ситуация наблюдалась нами в $\mathrm{MHC}\left(\mathrm{Co}_{45} \mathrm{Fe}_{45} \mathrm{Zr}_{10} / a-\mathrm{Si}\right)_{40}$ с прослойками из аморфного кремния варьируемой толщины в пределах $0.5-4.0 \mathrm{~nm}$ и толщинами металлических слоев $1.4-2.0 \mathrm{~nm}$ [16]. Неразрушающий послойный анализ этих МНС методом ультрамягкой рентгеновской спектроскопии (УМРЭС) показал, что в этом случае практически весь аморфный кремний прослоек расходуется на образование немагнитных силицидных фаз. И когда толщина такой прослойки превосходит толщину металлического слоя, то
МНС становятся немагнитными [13]. Тогда как в МНС $\left(\mathrm{Co}_{45} \mathrm{Fe}_{45} \mathrm{Zr}_{10} / \mathrm{SiO}_{2}\right)_{32}$ с оксидными прослойками толщина силицидных интерфейсов между металлическими слоями и прослойками $\mathrm{SiO}_{2}$ не превышает $0.1 \mathrm{~nm}[16]$, и центральные части прослоек остаются оксидными.

Целью данной работы является определение электронного строения и фазового состава неметаллических прослоек и интерфейсов в МНC $\left[(\mathrm{CoFeB})_{60} \mathrm{C}_{40} / \mathrm{SiO}_{2}\right]_{200}$, содержащей композитные слои $(\mathrm{CoFeB})_{60} \mathrm{C}_{40}$, чередующиеся с прослойками $\mathrm{SiO}_{2}$.

Свойства самих композитов $\left(\mathrm{Co}_{41} \mathrm{Fe}_{39} \mathrm{~B}_{20}\right)_{x} \mathrm{C}_{100-x}$ в широком интервале составов исследовались в работе [17]. Анализ контраста на темнопольном и светлопольном изображениях просвечивающего электронного микроскопа (ПЭМ) в пленках этих композитов выявил наличие металлических гранул размером $1-2 \mathrm{~nm}$, сгруппированных в областях 4-5 nm. Удельное сопротивление композита на перколяционном переходе при $x=62 \%$ составляет $2.18 \cdot 10^{-6} \Omega \cdot \mathrm{m}$. Выше этого перехода композит проявляет ферромагнитные свойства. При этом было установлено, что перколяционные переходы в композитах металл-углерод происходят при более высоких значениях $x$ по сравнению с композитами металл-диэлектрик .

\section{2. Методика получения многослойных наноструктур}

Многослойная наноструктура $\left[(\mathrm{CoFeB})_{60} \mathrm{C}_{40} / \mathrm{SiO}_{2}\right]_{200}$ была получена ионно-лучевым распылением двух мишеней на вращающуюся ситалловую подложку по методике [1]. Одна из мишеней представляла собой металлическую пластину сплава $\mathrm{Co}_{40} \mathrm{Fe}_{40} \mathrm{~B}_{20}$ со вставками графита, расположенными таким образом, чтобы атомный состав напыляемых композитных металлсодержащих слоев содержал около 40 at.\% углерода и соответствовал $(\mathrm{CoFeB})_{60} \mathrm{C}_{40}$. Вторая мишень представляла собой пластину кварца $\mathrm{SiO}_{2}$, из которой получали диэлектрические прослойки. Для создания градиента толщины композитных слоев и прослоек между мишенью и подложками устанавливался $V$-образный экран. Напыление проводилось в атмосфере $\mathrm{Ar}$ при давлении $5 \cdot 10^{-4}$ Torr в 2 этапа по $520 \mathrm{~min}$ при нанесении на ситалловую подложку 200 бислоев МНС.

\section{3. Рентгеноструктурные исследования МHC}

Рентгеноструктурные исследования МНС проводились на дифрактометре ДРОН-4 с Со $K_{\alpha}$-излучением в режиме пошагового сканирования. Так как МНС изготовлена с градиентом толщины бислоев, она была поделена на три части размером $15 \times 15 \mathrm{~mm}$. Полученные образцы были пронумерованы в сторону утолщения бислоев, № 1,2,3 соответственно. Нами были получены дифрактограммы от этих трех образцов МНС 


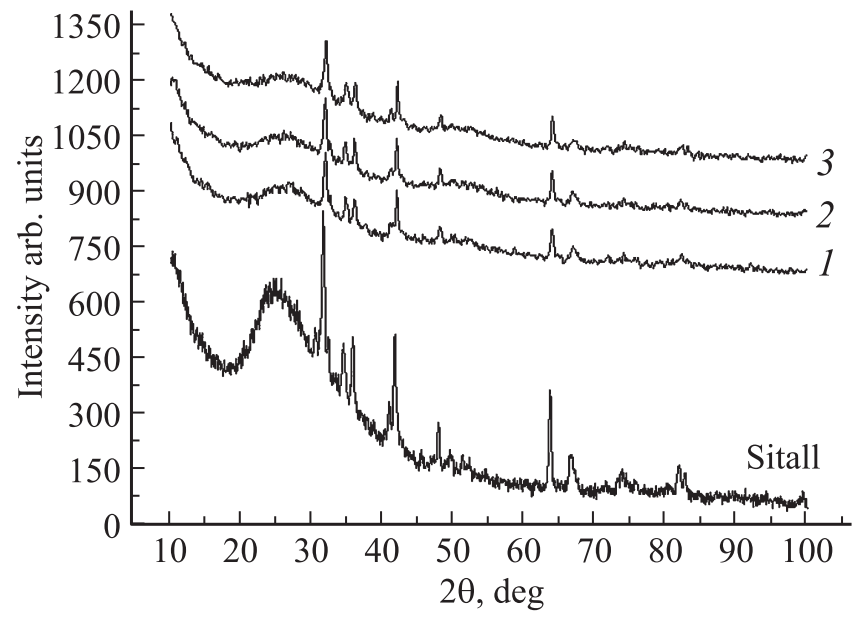

Рис. 1. Обзорные дифрактограммы образцов 1-3 наноструктуры $\left[(\mathrm{CoFeB})_{60} \mathrm{C}_{40} / \mathrm{SiO}_{2}\right]_{200}$ и подложки ситалла.

$\left[(\mathrm{CoFeB})_{60} \mathrm{C}_{40} / \mathrm{SiO}_{2}\right]_{200}$ и чистого ситалла для исключения из анализируемой дифрактограммы линий ситалловой подложки (рис. 1). Исходя из того, что МНС были получены методом ионно-лучевого распыления мишеней кварца $\mathrm{SiO}_{2}$ и составной мишени с аморфным сплавом $\mathrm{CoFeB}$, можно ожидать, что полученные образцы МHC будут аморфными. Для обработки полученных данных использовалась программа Origin 8.0.

Анализ полученных результатов, приведенных на рис. 1, показал, что все линии на обзорных дифрактограммах исследуемых образцов соответствуют линиям ситалла подложки, в том числе и первое гало с максимумом при $2 \Theta=25^{\circ}$. Однако в диапазоне углов $2 \Theta$ от $45^{\circ}$ до $60^{\circ}$ намечается второе гало от наноструктуры $\left.[\mathrm{CoFeB})_{60} \mathrm{C}_{40} / \mathrm{SiO}_{2}\right]_{200}$, интенсивность которого немного возрастает с увеличением толщины слоев МНС от образца № 1 к образцу № 3. В наших предыдущих исследованиях МНC другого состава $\left(\mathrm{CoFeZr} / \mathrm{SiO}_{2}\right)_{32}$, без углерода в металлических слоях, и содержащих в них цирконий вместо бора, были обнаружены дифракционные линии в этом же диапазоне, принадлежащие твердым растворам на основе объемо-центрированного кубического (ОЦК) $\alpha$-Fe [2]. Однако в нашей МНC $\left.[\mathrm{CoFeB})_{60} \mathrm{C}_{40} / \mathrm{SiO}_{2}\right]_{200}$ в указанном диапазоне никаких дифракционных линий от МНС, кроме слабого гало, не наблюдается. Следовательно, все компоненты исследуемой МНС, и композитные металлосодержащие слои с углеродом, и диэлектрические оксидные прослойки являются аморфными.

\section{4. Определение толщин слоев и бислоев МНС методом малоугловой дифракции}

Для определения толщин слоев аморфной МНС $\left[(\mathrm{CoFeB})_{60} \mathrm{C}_{40} / \mathrm{SiO}_{2}\right]_{200}$ с композитными металлосодержащими слоями (Мe), чередующимися с диэлектрическими прослойками $\mathrm{SiO}_{2}$, был использован метод
Таблица 1. Толщины бислоев/слоев $(\AA)$ по данным малоугловой дифракции в различных порядках отражения

\begin{tabular}{c|l|l|c|r|r|c}
\hline $\begin{array}{c}\text { № } \\
\text { пика }\end{array}$ & $\begin{array}{c}2 \Theta, \\
\text { deg. }\end{array}$ & $\begin{array}{c}\Theta, \\
\text { deg. }\end{array}$ & $\begin{array}{c}d \\
(n=1)\end{array}$ & $\begin{array}{c}d \\
(n=2)\end{array}$ & $\begin{array}{c}d \\
(n=3)\end{array}$ & $\begin{array}{c}d \\
(n=4)\end{array}$ \\
\hline 1 & 0.99 & 0.495 & 89.23 & 178.47 & 267.70 & 356.94 \\
2 & 1.55 & 0.775 & $\mathbf{5 7 . 0 0}$ & 113.99 & 170.99 & 227.98 \\
3 & 2.22 & 1.11 & $\mathbf{3 9 . 8 0}$ & 79.59 & 119.39 & 159.18 \\
4 & 2.91 & 1.455 & 30.36 & $\mathbf{6 0 . 7 2}$ & 91.08 & 121.44 \\
5 & 3.6 & 1.8 & 24.54 & 49.09 & 73.63 & 98.17 \\
6 & 4.3 & 2.15 & $\mathbf{2 0 . 5 5}$ & $\mathbf{4 1 . 1 0}$ & $\mathbf{6 1 . 6 5}$ & 82.20 \\
7 & 4.98 & 2.49 & 17.74 & 35.49 & 53.23 & 70.98 \\
8 & 5.69 & 2.845 & 15.53 & 31.06 & 46.60 & $\mathbf{6 2 . 1 3}$ \\
9 & 6.38 & 3.19 & 13.85 & 27.71 & $\mathbf{4 1 . 5 6}$ & 55.41 \\
10 & 7.1 & 3.55 & 12.45 & 24.90 & 37.35 & 49.80 \\
11 & 7.81 & 3.905 & 11.32 & 22.64 & 33.96 & 45.28 \\
12 & 8.5 & 4.25 & 10.40 & $\mathbf{2 0 . 8 1}$ & 31.21 & $\mathbf{4 1 . 6 1}$ \\
13 & 9.23 & 4.615 & 9.58 & 19.16 & 28.74 & 38.33
\end{tabular}

малоугловой дифракции на дифрактометре ARLX'TRA в геометрии параллельного пучка (оптическая схема: параболическое зеркало-тонкопленочный коллиматор). Съемку производили в режиме $\Theta-\Theta$ в интервале углов $1-10^{\circ}(2 \Theta)$. В качестве источника рентгеновского излучения служила рентгеновская трубка с $\mathrm{Cu} K_{\alpha}$-излучением, дискриминация неупруго-рассеянного излучения осуществлялась полупроводниковым энергодисперсионным детектором с разрешением $250 \mathrm{eV}$ и охладителем на элементах Пельтье. Прибор был откалиброван по стандартному образцу NISTRM-1976а, погрешность положения рефлексов относительно эталона не превышала $0.010^{\circ} 2 \Theta$.

Дифрактограмма исследуемого образца МНС $\left[(\mathrm{CoFeB})_{60} \mathrm{C}_{40} / \mathrm{SiO}_{2}\right]_{200}$, близкого по толщинам слоев к среднему по толщинам образцу № 2, полученная в интервале углов $1-10^{\circ}(2 \Theta)$, приведена на рис. 2 , на котором цифрами снизу обозначены номера последовательных дифракционных отражений от МНС.

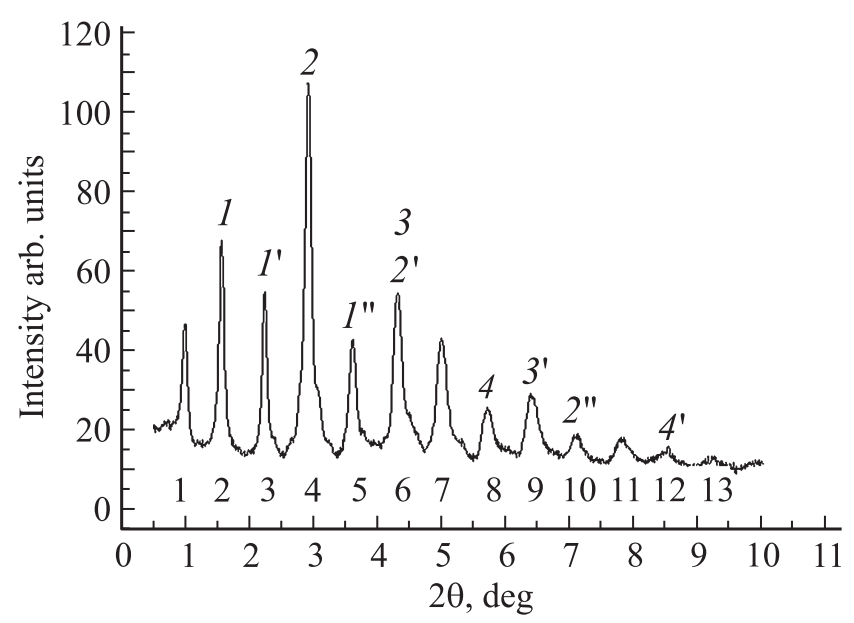

Рис. 2. Малоугловая дифракция МНC $\left[(\mathrm{CoFeB})_{60} \mathrm{C}_{40} / \mathrm{SiO}_{2}\right]_{200}$. 
Расчет максимумов дифракционных отражений (табл. 1) производился в соответствии с формулой Вульфа-Брэггов $2 d \cdot \sin \Theta=n \lambda$, в которой $d$ соответствует толщине бислоев (толщина металлосодержащего слоя $d_{1}+$ толщина диэлектрической прослойки $\left.d_{2}\right)$, или расстоянию между границами металлосодержащих слоев $d_{1}$, или расстоянию между границами диэлектрических прослоек $d_{2} . n$ соответствует порядкам отражения, которые на рис. 2 указаны цифрами над максимумами дифракционных отражений.

Результаты, приведенные на рис. 2 и в табл. 1, показывают, что МНС дает 4 порядка отражений от бислоев толщиной около $6 \mathrm{~nm}$ (номера линий 2(1), 4(2), $6(3), 8(4))$, цифрами в круглых скобках обозначения порядки отражения; 4 порядка отражения от границ металлосодержащих слоев $(\mathrm{CoFeB})_{60} \mathrm{C}_{40}$ толщиной $d_{1}$ около $4 \mathrm{~nm}$ (номера линий $3\left(1^{\prime}\right), 6\left(2^{\prime}\right), 9\left(3^{\prime}\right), 12\left(4^{\prime}\right)$ ), цифрами в одним штрихом в круглых скобках обозначены порядки отражения; 2 порядка отражений от границ диэлектрических слоев $\mathrm{SiO}_{2}$ толщиной $d_{2}$ около $2 \mathrm{~nm}$ (номера линий 5(1”), 10(2”) цифрами с двумя штрихами в круглых скобках обозначены порядки отражения. В табл. 1 выделены жирным шрифтом значения толщин бислоев $d$ для 4-х порядков отражения; толщины металлосодержащих слоев $d_{1}$ также для 4-х порядков отражения и толщины диэлектрических прослоек $d_{2}$ для двух порядков отражения. Следует учитывать, что точность определения периодов сверхструктур (в данном случае толщин бислоев и слоев) в области малых брэгговский углов (около одного градуса) составляет $1-2 \AA$.

\section{5. Определение фазового состава аморфных диэлектрических прослоек МНС методом ультрамягкой рентгеновской эмиссионной спектроскопии}

Далее для определения фазового состава аморфных диэлектрических прослоек в МHC $\left[(\mathrm{CoFeB})_{60} \mathrm{C}_{40} / \mathrm{SiO}_{2}\right]_{200}$, получаемых ионно-лучевым распылением кварцевой мишени, мы использовали неразрушающий метод ультрамягкой рентгеновской эмиссионной спектроскопии (УМРЭС) путем регистрации $\mathrm{Si} L_{2,3}$-спектров кремния при разных значениях высокого напряжения на рентгеновской трубке, отражающих распределение плотности занятых $(s+d)$ состояний в валентной зоне. Варьирование ускоряющего напряжения $V$ на рентгеновской трубке спектрометра PCM-500 в пределах от 1 до $6 \mathrm{kV}$ позволяет исследовать без разрушения образца все более толстые слои МНС от $10 \mathrm{~nm}$ при $V=1 \mathrm{kV}$ до $120 \mathrm{~nm}$ при $V=6 \mathrm{kV}$, подобно тому, как это мы делали ранее при исследовании МНC других составов [16].

На рис. 3 приведены $\mathrm{Si} L_{2,3}$-спектры кремния от образцов № 1-3 МНС для двух толщин диагностируемых
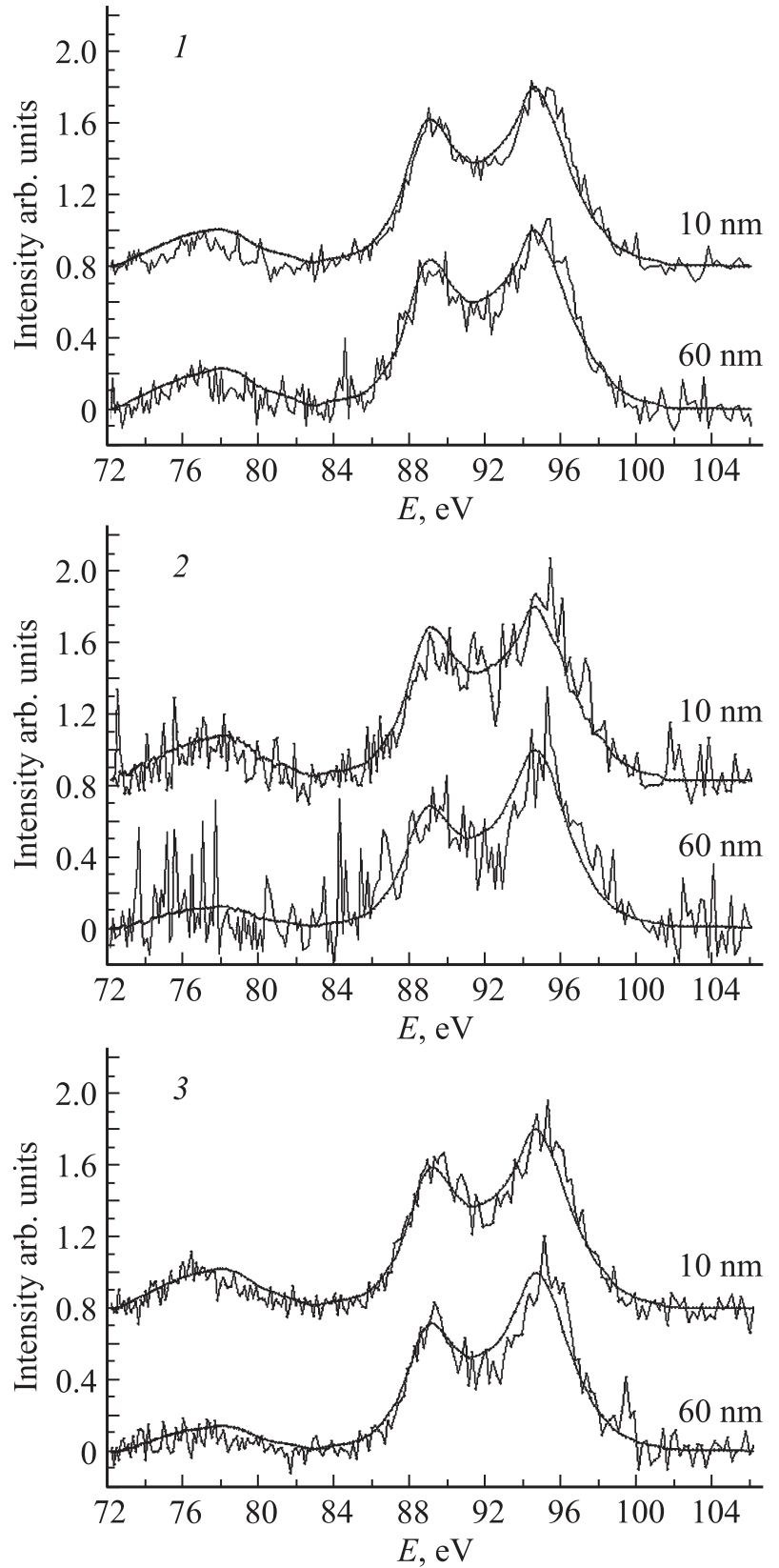

Рис. 3. Экспериментальные $\mathrm{Si} \quad L_{2,3}$-спектры $\mathrm{MHC}$ $\left[(\mathrm{CoFeB})_{60} \mathrm{C}_{40} / \mathrm{SiO}_{2}\right]_{200}$, и моделированные спектры (тонкие линии).

слоев $(10$ и $60 \mathrm{~nm})$, поскольку спектры от слоев толщиной $120 \mathrm{~nm}$ фактически повторяют форму спектров от слоев $60 \mathrm{~nm}$.

$\mathrm{Si} L_{2,3}$-спектры кремния для всех трех образцов, приведенные на рис. 3, имеют форму, характерную для оксидов кремния (рис. 4), с небольшой вариацией относительной интенсивности двух главных пиков спектра. Такая вариация свидетельствует об изменениях стехиометрии оксидов кремния во всех исследованных нами образцах МНС по сравнению с диоксидом кремния стехиометрического состава, приведенном в качестве одного из эталонов на рис. 4. 


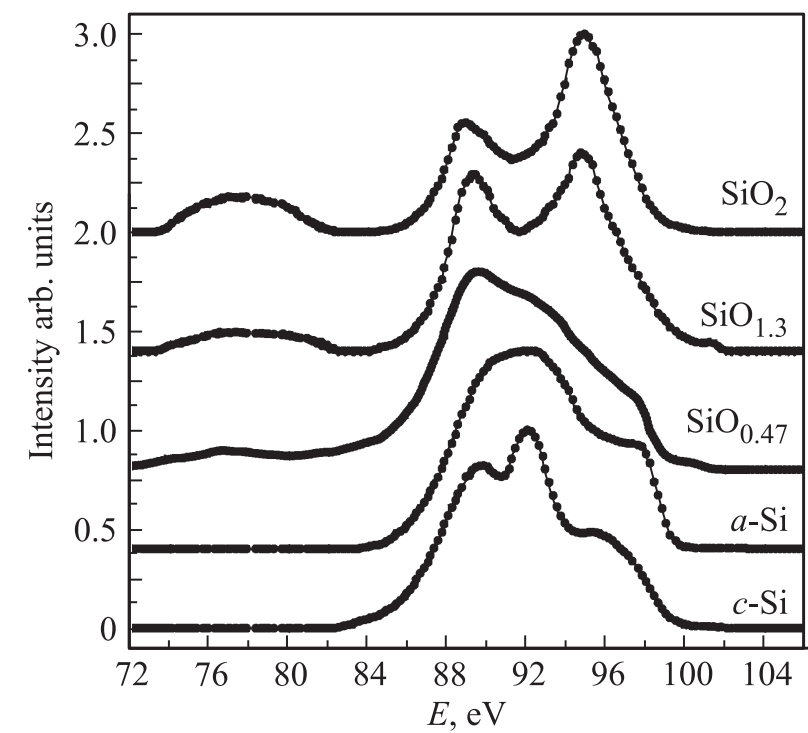

Рис. 4. Эталонные $\mathrm{Si} L_{2,3}$-спектры кремния: монокристаллического $c$ - $\mathrm{Si}$, аморфного $a$ - $\mathrm{Si}$, субоксидов $\mathrm{SiO}_{0.47}$ и $\mathrm{SiO}_{1.3}$ и диоксида $\mathrm{SiO}_{2}$.

$\mathrm{B}$ стехиометрическом $\mathrm{SiO}_{2}$ отношение интенсивности низкоэнергетического пика (при $90 \mathrm{eV}$ ) к высокоэнергетическому (около $95 \mathrm{eV}$ ) соответствует 0.6. Хорошо известно, что образование химических связей кремния с кислородом приводит к постепенному перемещению главного максимума плотности состояний от $92 \mathrm{eV}$ у элементарного кремния и низшего субоксида $\mathrm{SiO}_{0.47}$ (рис. 4) к главному максимуму при $95 \mathrm{eV}$, расположенному в области энергий связующей О $2 p$-орбитали кислорода в субоксиде $\mathrm{SiO}_{1.3}$ и диоксиде кремния $\mathrm{SiO}_{2}$. При этом часть плотности $s$-состояний кремния оказывается в энергетической области О $2 s$-орбитали кислорода и проявляется в виде длинноволнового сателлита при $77-76 \mathrm{eV}$.

Для определения фазового состава аморфных диэлектрических прослоек $\mathrm{MHC}\left[(\mathrm{CoFeB})_{60} \mathrm{C}_{40} / \mathrm{SiO}_{2}\right]_{200}$ были использованы алгоритм и разработанная нами математическая методика анализа сложной формы рентгеновского эмиссионного спектра валентной полосы образца путем сравнения моделированного спектра из нескольких эталонных спектров кремния $\mathrm{Si} L_{2,3}$ от известных фаз с экспериментальным [18]. На рис. 4 приведены эталонные $\mathrm{Si} L_{2,3}$-спектры кремния, которые были использованы

Таблица 2. Относительное содержание субоксидной и диоксидной фаз кремния в диэлектрических прослойках МНС $\left[(\mathrm{CoFeB})_{60} \mathrm{C}_{40} / \mathrm{SiO}_{2}\right]_{200}$

\begin{tabular}{c|c|c|c|c|c|c}
\hline \multirow{2}{*}{$\begin{array}{c}\text { Глубина } \\
\text { анализа }\end{array}$} & \multicolumn{2}{|c|}{ Образец 1 } & \multicolumn{2}{c|}{ Образец 2 } & \multicolumn{2}{c}{ Образец 3 } \\
\cline { 2 - 7 } & $\begin{array}{c}\mathrm{SiO}_{1,3}, \\
(\%)\end{array}$ & $\begin{array}{c}\mathrm{SiO}_{2}, \\
(\%)\end{array}$ & $\begin{array}{c}\mathrm{SiO}_{1,3}, \\
(\%)\end{array}$ & $\begin{array}{c}\mathrm{SiO}_{2}, \\
(\%)\end{array}$ & $\begin{array}{c}\mathrm{SiO}_{1,3}, \\
(\%)\end{array}$ & $\begin{array}{c}\mathrm{SiO}_{2}, \\
(\%)\end{array}$ \\
\hline $10 \mathrm{~nm}(1 \mathrm{kV})$ & 65 & 35 & 80 & 20 & 70 & 30 \\
$60 \mathrm{~nm}(3 \mathrm{kV})$ & 75 & 25 & 40 & 60 & 50 & 50
\end{tabular}

при моделировании: монокристаллического $c$ - $\mathrm{Si}$, аморфного $a-\mathrm{Si}$, субоксидов $\mathrm{SiO}_{0.47}, \mathrm{SiO}_{1,3}$ и диоксидов $\mathrm{SiO}_{2}$. Моделированные спектры наложены на экспериментальные спектры тонкими линиями на рис. 3.

В табл. 2 приведены значения относительного содержания в процентах субоксидной фазы $\mathrm{SiO}_{1.3}$ и диоксидной фазы кремния $\mathrm{SiO}_{2}$ в диэлектрических прослойках MHC $\left[(\mathrm{CoFeB})_{60} \mathrm{C}_{40} / \mathrm{SiO}_{2}\right]_{200}$, полученные по результатам моделирования с эталонными спектрами рис. 4, для двух различных глубин анализа, задаваемых вариацией высокого напряжения на аноде рентгеновской трубки спектрометра РСМ-500. Отклонение экспериментальных спектров от моделированных в среднем составляет около $25 \%$.

Результаты моделирования, представленные в табл. 2, показывают, что не менее половины состава диэлектрического слоя составляет субоксид $\mathrm{SiO}_{1,3}$, более близкий к монооксиду кремния. Наличие такой фазы с большим числом вакансий по кислороду неизбежно приводит к появлению локализованных состояний в запрещенной зоне, снижает изолирующие свойства прослоек и должно приводить к появлению прыжковой проводимости в нормальном направлении к слоям МНС.

Таким образом, результаты моделирования экспериментальных УМРЭС Si $L_{2,3}$-спектров кремния аморфной $\mathrm{MHC}\left[(\mathrm{CoFeB})_{60} \mathrm{C}_{40} / \mathrm{SiO}_{2}\right]_{200}$, содержащей чередующиеся композитные металл-углеродные слои и диэлектрические прослойки, указывают на существенное отклонение стехиометрического состава диэлектрических прослоек от стехиометрии распыляемого кварца в сторону уменьшения содержания кислорода с образованием субоксида $\mathrm{SiO}_{1,3}$.

Кроме того, немаловажным является факт отсутствия влияния на тонкую структуру $\mathrm{Si} L_{2,3}$-спектров силицидообразования на интерфейсах композитный металл-углеродные слой/оксидная прослойка, которое мы наблюдали в МНС без углерода в металлических слоях [16].

\section{6. Заключение}

Сопоставляя полученные данные рентгеноспектральных УМРЭС и РД исследований МНС $\left[(\mathrm{CoFeB})_{60} \mathrm{C}_{40} / \mathrm{SiO}_{2}\right]_{200}$, с ранее полученными результатами исследований $\mathrm{MHC}\left(\mathrm{Co}_{45} \mathrm{Fe}_{45} \mathrm{Zr}_{10} / \mathrm{SiO}_{2}\right)_{32}$ с такими же оксидными прослойками различной толщины [16], следует отметить их отличительную особенность, состоящую в том, что все компоненты исследуемой $\mathrm{MHC}$, как композитные металлосодержащие слои с углеродом, так и диэлектрические оксидные прослойки являются аморфными.

Тем не менее, несмотря на аморфное состояние чередующихся композитных слоев и оксидных прослоек, они сохраняют планарные межфазные границы, в результате чего полученная МНС образует сверхструктуру из бислоев с периодом $6 \mathrm{~nm}$, дающую четкие дифракционные максимумы в четырех порядках отражения. 
Кроме того, в настоящем исследовании мы не обнаружили силицидных фаз $3 d$-металлов на интерфейcax композит/диэлектрическая прослойка, в отличие от предыдущих исследований $\mathrm{MHC}\left(\mathrm{Co}_{45} \mathrm{Fe}_{45} \mathrm{Zr}_{10} / \mathrm{SiO}_{2}\right)_{32}$ нашей работы [16], в которой трансформация тонкой структуры $\mathrm{Si} L_{2,3}$-спектров кремния МНC при малых толщинах неметаллической прослойки $(0.5 \mathrm{~nm})$ позволила оценить порядок толщины силицидных интерфейсов около $0.1 \mathrm{~nm}$. Отсутствие силицидообразования на интерфейсах исследуемой многослойной структуры $\left[(\mathrm{CoFeB})_{60} \mathrm{C}_{40} / \mathrm{SiO}_{2}\right]_{200}$ может быть связано с ,экранирующим“ действием углерода в металлосодержащих слоях и должно способствовать увеличению анизотропии электромагнитных свойств МНС.

\section{Список литературы}

[1] О.В. Стогней, Ю.Е. Калинин, А.В. Ситников, И.В. Золотухин, А.В. Слюсарев. ФММ 91, 24 (2001).

[2] Yu.E. Kalinin, A.V. Sitnikov, O.V. Stogney, I.V. Solotuhin. Mater. Sci. Eng. 304-306, 941 (2001).

[3] Э.П. Домашевская, С.А. Сторожилов, С.Ю. Турищев, В.М. Кашкаров, В.А. Терехов, О.В. Стогней, Ю.Е. Калинин, А.В. Ситников, С.Л. Молодцов. ФТТ 50, 135 (2008).

[4] E.P. Domashevskaya, S.A. Storozhilov, S.Yu. Turishchev, V.M. Kashkarov, V.A. Terekhov, O.V. Stognej, Yu.E. Kalinin, S.L. Molodtsov. J. Electron Spectroscopy Rel. Phenomena 156-158, 180 (2007).

[5] В.О. Васьковский, Г.С. Патрин, Д.А. Великанов, А.В. Свалов, П.А. Савин, А.А. Ювченко, Н.Н. Щеголева. ФТТ 49, 291 (2007).

[6] Л.А. Чеботкевич, А.В. Огнев, Ю.П. Иванов, К. Lenz, А.И. Ильин, К.С. Ермаков. ФТТ 51, 1761 (2009).

[7] R.S. Iskhakov, S.V. Stolyar, V.Yu. Yakovchuk, M.V. Chizhik. Solid State Phenomena 168-169, 69 (2011).

[8] A.B. Pakhomov, X. Yan. Solid State Commun. 99, 139 (1996).

[9] Б.А. Аронзон, Д.Ю. Ковалев, А.Н. Лагарьков.,Е.З. Мейлихов, В.В. Рыльков, М.А. Седова, Н. Негре, М. Гойран, Дж. Леотин. Письма в ЖЭТФ 2, 87 (1999).

[10] И.В. Быков, Е.А. Ганьшина, А.Б. Грановский, В.С. Гущин, А.А. Козлов, Т. Масумото, С. Онума. ФТТ 2, 268 (2005).

[11] A.M. Kadigrobov, M.V. Fistul, K.B. Efetov. Phys. Rev. B 73, 235 (2006)

[12] Ju. Chekrygina, A. Devizenko, Yu. Kalinin, E. Lebedeva, I. Shipkova, A. Sitnikov, N. Syr'ev, S. Vyzulin. Solid State Phenomena 190, 605 (2012).

[13] Б.А. Аронзон, А.Б. Грановский, А.Б. Давыдов, М.Е. Докукин, Ю.Е. Калинин, С.Н. Николаев, В.В. Рыльков, А.В. Ситников, В.В. Тугушев. ЖЭТФ 130, 127 (2006).

[14] Э.П. Домашевская, А.В. Чернышев, С.Ю. Турищев, Ю.Е. Калинин, А.В. Ситников, Д.Е. Марченко. ФТТ 55, 1202 (2013).

[15] Э.П. Домашевская, А.В. Чернышев, С.Ю. Турищев, Ю.Е. Калинин, А.В. Ситников, Д.Е. Марченко. ФТТ 56, 2219 (2014).

[16] Э.П. Домашевская, В.А. Терехов, С.Ю. Турищев, Д.Е. Спирин, А.В. Чернышев, Ю.Е. Калинин, А.В. Ситников. ФТТ 58, 991 (2016).

[17] А.А. Абрычкин, А.А. Алешников, Ю.Е. Калинин, А.В. Ситников, О.С. Тарасова Вестн. Воронежского гос. техн. ун-та 8, 71 (2012).

[18] Э.Ю. Мануковский. Автореферат канд. дисс. Воронеж. ВГУ (2000) 16 с. 